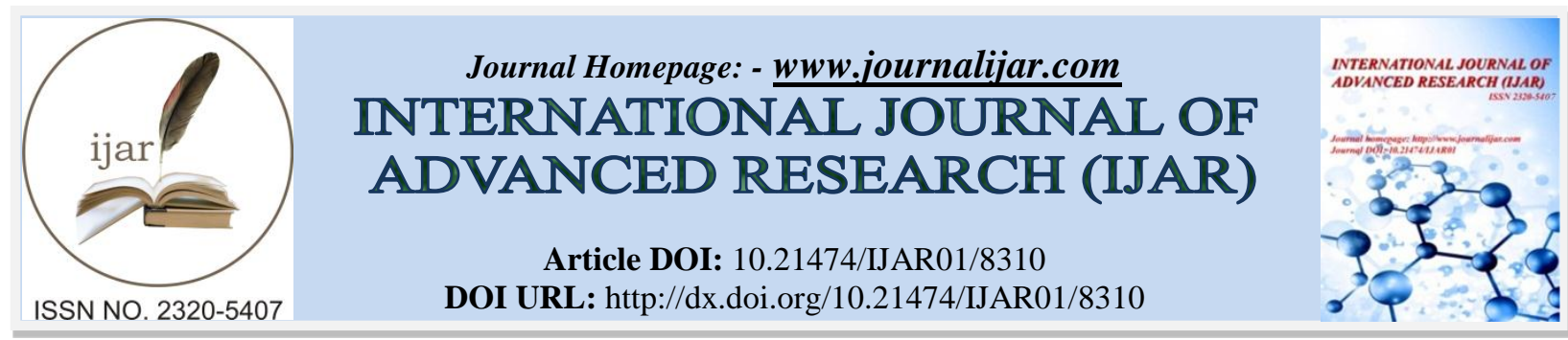

RESEARCH ARTICLE

\title{
INSIGHTS INTO VIRULENCE AND ANTIMICROBIAL RESISTANCE PLASMID ASSOCIATED GENES OF ESBL ESCHERICHIA COLI ASSOCIATED WITH ARTHRITIS IN CHICKENS IN EGYPT.
}

Ashraf A. Abd El-Tawab ${ }^{1}$, Fatma I. El-Hofy ${ }^{1}$, khalid I. Alekhnawy ${ }^{2}$, Asmaa T. Talaie ${ }^{2}$ and Ahmed A. Hefny ${ }^{3}$

1. Bacteriology, Immunology and Mycology Department, Faculty of Veterinary Medicine, Benha University, Egypt.

2. Animal Health Research Institute, Tanta branch, Egypt.

3. Veterinary Hospital, Faculty of Veterinary Medicine, Zagazig University, 44511, Egypt.

\section{Manuscript Info}

[........................

\section{Manuscript History}

Received: 04 November 2018

Final Accepted: 06 December 2018

Published: January 2019

Keywords:

arthritis, E. coli, ESBL, antibiotic resistance, plasmid associated genes.

\begin{abstract}
Increasing the incidence of extended spectrum beta-lactamase (ESBL) among Enterobacteriaceae especially avian pathogenic Escherichia coli (APEC) is of great concern to poultry industry. This study aimed to detect the prevalence and resistant profile of isolates showed ESBL activity among $100 \mathrm{E}$. coli isolates collected from hock joints in chickens (14-70 days old) with arthritis symptoms, from different chicken farms at EL-Gharbia Governorate in Egypt, in addition to, detect the incidence rates for selections of some virulence and antibiotic resistance plasmid associated genes using conventional PCR. A total 40 isolates were phenotypically identified as E. coli, with predominant (50\%) O125 serotypes. All (100\%) E. coli strains demonstrated a high level of multidrug resistance (MDR). Meanwhile, only $5(12.5 \%)$ isolates were identified as ESBL producers based phenotypically on double disc synergy test and genotypically on screening for presence of $\beta$-lactamases genes. The ESBL isolates showed high resistance rates to $\beta$-lactam, aminoglycoside, tetracycline and quinolones antimicrobials, which could be explained by the presence of (100\%) bla $a_{\text {TEM }},(100 \%)$ aad $\mathrm{A},(80 \%)$ tet $\mathrm{A}$ and (20\%) qnr $\mathrm{S}$ resistance genes, respectively. Regarding virulence genes, the result showed that only iss and ompA genes were detected in all isolates showed ESBL activity. The co-occurrence of these antibiotic resistance and virulence plasmid associated genes confirmed the acquisition of antimicrobial resistance genes by ESBL producing E. coli, which associated with increased virulence. Thus, urgent intervention is needed to successfully control contamination with MDR isolates in Egypt especially in poultry and its products.
\end{abstract}

Copy Right, IJAR, 2018,. All rights reserved.

\section{Introduction:-}

Escherichia coli is normal inhabitant in intestine of chicken but certain strains of avian pathogenic Escherichia coli spread into different internal organs causing colibacillosis, which is characterized by septicemia with multiple organ

Corresponding Author:-Ashraf A. Abd El-Tawab.

Address:-Bacteriology, Immunology and Mycology Department, Faculty of Veterinary Medicine,

Benha University, Egypt. 
lesions. Arthritis is the most common forms of colibacillosis lead to economic losses due to decrease in body weight, emaciation and deaths between infected chicken (Oh et al. 2011).

Antimicrobial resistance assessment of APEC at molecular level may be a useful tool for understanding the role of genetic elements in developing, dissemination and persistence of resistance in bacteria (Alekshun and Levy 2007). Recently, drug resistance has increased dramatically all over the world, especially, the broad-spectrum cephalosporins resistance which is very important in the care of human health, which conducted mainly to the spread of genes encoding extended spectrum beta-lactamases ( $\mathrm{Su}$ et al. 2008). One of the main concerns about ESBL genes located in mobile genetic elements that can easily be transferred between and within bacterial species, in addition, it can carry different virulence and antibiotic resistance genes (Hawkey and Jones 2009). Therefore, it is strongly recommended that ESBL detection is carried out systematically for all bacteriaceae. The most common types of plasmid borne $\beta$-lactamases in resistant E. coli isolates in Egypt are TEM-, SHV- and OXA-type (Ahmed et al. 2015).

The ESBL producing members are resistant to penicillins, cephalosporins, and aztreonam, and frequently resistant to aminoglycosides, trimethoprim-sulfamethoxazole, and quinolones. Thus, resistance caused by these enzymes increase the frequent of treatment failures in humans (Dutil et al. 2010). Recently, WHO (2014) reported high resistance rates to third generation cephalosporins in Egypt.

Therefore, the current study aimed primary on the prevalence of ESBL isolates among multidrug resistant $E$. coli isolates associated with hock joint infections between chickens in Egypt, in addition to, detect the incidence rates for selections of some virulence and antibiotic resistance plasmid associated genes using conventional PCR.

\section{Materials and Methods:- \\ Bacterial isolates}

A total of 100 samples were collected from hock joints in chickens (14-70 days old) with arthritis symptoms, from different chicken farms at EL-Gharbia Governorate in Egypt. All samples were subjected for isolation and biochemical identification of Escherichia coli according to Quinn et al. (2002). For further confirmation, API20E system (BioMérieux, France) was used for identification of all biochemically identified isolates. The biochemically identified E. coli isolates were serotyped according to Edward and Ewings (1972), using agglutination test in serology unit in animal health research institute, Dokki, Egypt.

\section{Antimicrobial susceptibility testing}

The antimicrobial susceptibility testing was performed for all E. coli identified isolates according to the Kirby Bauer disk diffusion method (Finegold and Martin 1982), using Mueller Hinton agar using discs (Oxoid) of different antibiotic groups; $\beta$-lactam (amoxicillin; AML $10 \mu \mathrm{g}$ ), tetracycline (doxycycline; DO $30 \mu \mathrm{g}$ ), aminoglycoside (gentamycin; CN $10 \mu \mathrm{g}$, and streptomycin; S $10 \mu \mathrm{g}$ ) and quinolones (ciprofloxacin; CIP $5 \mu \mathrm{g}$ ). The results were interpreted according to the criteria recommended by CLSI (2011). Each isolate was examined in triplicate. Isolates showed resistant to more than two different antibiotic groups were considered as MDR isolates.

\section{ESBL isolates and their antibiotic resistance and virulence plasmid associated genes}

The screening for ESBL activity was applied for all confirmed multi-resistant $E$. coli strains by double disc synergy test using cefotaxime and ceftazidime disks with and without clavulanic acid (Mast Diagnostics, Merseyside, UK) (CLSI 2014). The DNA from phenotypically identified ESBL isolates was extracted using QIAamp DNA mini kit (Cat. no. 51304; Qiagen). Screening for the presence of $\beta$-lactamases genes (blaTEM, blaSHV, and blaCTX-M), in addition to a selection of some virulence and antibiotic resistance plasmid associated genes was carried out by conventional PCR. The primers and probes used for amplification of different genes and size of PCR amplicons used in the current study were presented in Table 1. E. coli ATCC 25922 and Klebsiella pneumoniae ATCC 700603 were used negative and positive quality control strains, respectively.

\section{Results:-}

\section{Isolation and identification of $E$. coli}

Based on phenotypic characters, $40 \mathrm{E}$. coli isolates were preliminary identified from 100 samples obtained from hock joints of chicken showing arthritic symptoms. The preliminary identification was based on their colonial morphology; pink colonies on MacConkey agar and characteristic green metallic sheen colonies on Eosin Methylene 
Blue agar. The identical biochemical characters showed positive reaction with indole test and negative reaction with Simmon's Citrate agar, in addition to yellow slant and butt with gas formation on Triple Sugar Iron agar medium, while, negative results were obtained with urease test with no $\mathrm{H}_{2} \mathrm{~S}$ production. Furthermore, all identified isolates were confirmed as E. coli by API $20 \mathrm{E}$ system. The serotyping of isolates revealed two predominant O serotypes; (50\%) 0125 and (20\%) O27. In addition, O86a, O127 and O78 serotypes (10\%, each) were detected.

\section{Antimicrobial susceptibility testing}

The antibiotic resistance profiles of the $40 \mathrm{E}$. coli isolates demonstrated high rates of resistance to amoxicillin and streptomycin $(100 \%$, each), followed by doxycycline $(80 \%)$ and ciprofloxacin $(70 \%)$. The lower resistant rate was detected with gentamycin (35\%). Regarding MDR, All (100\%) All E. coli strains exhibited resistance to three antibiotics at least, thus, showed high level of multi-drug resistance.

\section{ESBL isolates and their virulence and antibiotic resistance plasmid associated genes}

Out of 40 MDR E. coli isolates, 5 (12.5\%) isolates showed ESBL activity based on double disc synergy test. Regarding $\beta$-lactamase genes, these isolates harbored only blaTEM gene, Figure 1. The ESBL isolates showed $60 \%$, $60 \%, 80 \%, 100 \%$ and $100 \%$ resistance rates for ciprofloxacin, gentamycin, tetracycline, amoxicillin and streptomycin, respectively. The phenotypic resistance to $\beta$-lactam, aminoglycoside, tetracycline and quinolones antimicrobials could be explained by the presence of (100\%) blaTEM, (100\%) aadA, (80\%) tet A and (20\%) qnrS resistance genes, respectively, among the isolates showed ESBL activity. Regarding virulence genes, the result showed that iss and ompA genes were detected in all isolates showed ESBL activity, while none of eaeA and CFA/I genes were detected (Table 3).

\section{Discussion:-}

Avian pathogenic $E$. coli is one of major causes of morbidity and mortality in chicken and associated with economic losses (Smith et al. 2007). The result showed high prevalence rate of (40\%) E. coli isolates, which indicated its potential role in avian pathogens associated with arthritis in Egypt. Similar result was recorded in Bangladesh (Rahman et al. 2004). However, higher level of prevalence was reported in (60\%) Egypt (Tawfik et al. 2016), while, lower prevalence rate was reported in (7.8\%) Iraq (Rasheed 2011). The variation in prevalence rates were might be conducted to many factors, including birds; age, breed, immune status and medication during sample collection, environment and hygienic measure inside farms (El Tawab et al. 2015), in addition to status of affected joint during sampling if closed or opened (Tawfik et al. 2016). Also, the sampling scheme and detection protocol might play a role (Ammar et al. 2015).

In the last century, Orskov et al. (1977) reported a serotyping system for E. coli strains based on O- antigen. This system has been the basis for distinguishing strains during outbreaks, in addition for surveillance. In the current study, serological identification of $E$. coli isolates revealed five different O-serotypes (O86a, O127, O125, O78 and O27), were detected, and the predominant serotype was (50\%) O125. Similar observation was reported previously in Egypt (Tawfik et al. 2016). Thus, they might confirm their role particularly in adaptation and involvement in extra intestinal colibacillosis infections, especially, in arthritis infection in chicken farms in Egypt. On the other hand in USA, Gomis et al. (2001) reported that the predominant serotypes were O1, O6, O8, O15 and O78. Also, Abd ElMongy et al. (2018) detected seven serotypes; O2, O26, O78, O127, O1, O91 and O153. These variations reflect that E. coli serotypes are country specific or area specific. However, the health status of the birds, management strategies and climatic conditions might be playing a role in a specific serotype occurrence and its role in disease production (Srinivasan et al. 2013).

Intensive use of antimicrobial drugs especially in the poultry industry is causing increased resistance to antibiotics commonly used and increased incidence of multi-drug resistant strains (WHO 2014). In the current study, E. coli isolates showed high rates of resistance to streptomycin and amoxicillin followed by doxycycline and ciprofloxacin. In accordance, many studies in Egypt reported high level of resistance rates among APEC against different groups of antibiotics (Eid and Erfan 2013; Ammar et al. 2015; Shaza 2016), which attributed to the regular usage of these antibiotics for infection control in poultry industry in many district in Egypt. Moreover, antimicrobials are also administered at sub-therapeutic doses to prevent infections or assist in stress management or promote growth. Thus, the discrepancies in rates of E. coli resistance between countries appear to be due to differences in the level of dependence on certain groups of antimicrobial and management practices in poultry production, as well as differences in legislation that guide the use of antimicrobials from country to another (Sahoo et al. 2012). 
In the current study, the high levels of antibiotic resistance were detected, indicating the increase in multidrug resistance frequencies in E. coli isolates. Similar results were reported in Egypt (Eid and Erfan 2013). Meanwhile, six different antibiotic resistance patterns were detected in the current study. In accordance, several studies demonstrated several resistance patterns among their E. coli isolates in Egypt (Ammar et al. 2015) and Zimbabwe (Saidi et al. 2012). These results highlight the importance of establishing rules and legislations to regulate the excessive use of antibiotics in Egypt.

Out of 40 MDR E. coli isolates, 5 (12.5\%) isolates were phenotypically identified based on double disc synergy test as ESBL producers. Then, they were screened for beta lactamase genes, where, only blaTEM gene was detected in all isolates had ESBL activity. The incidence rate of different beta lactamase genes in Enterobacteriaceae was varied in several studies in Egypt; in septicemic broilers (El-Shazly et al. 2017), mastitic cows (Ahmed and Shimamoto 2011), and humans (Al-Agamy 2013). The epidemiology of ESBL genes is changing rapidly and shows marked geographic differences (Hawkey and Jones 2009). In the current study, the ESBL producing E. coli strains were detected in the diseased chickens of two farms, which assuming either B-lactam antibiotic pressure or initial farms contamination due to improper cleaning and disinfection (Laube et al. 2013; Blaak et al. 2014).

On the other hand, ESBL producing E. coli strains showed high rate of resistance to amoxicillin, streptomycin (100\%, each), doxycycline (80\%), ciprofloxacin and gentamycin (60\%, each). In accordance, the high degrees of antimicrobial resistance were reported in Egypt in chickens (El-Shazly et al. 2017) and humans (Khater and Sherif 2014). Based on previous data, the antimicrobial resistance rates are widespread in Egypt. Furthermore, isolates showing ESBL activities are usually play a role in cross resistant to other antibiotics due to the presence of different resistance genes on the same mobile genetic elements (Machado et al. 2005). The molecular investigations of resistance mechanisms in the current study revealed that resistance of ESBL producing E. coli isolates to amoxicillin, streptomycin and doxycycline antimicrobials could be explained by the presence of blaTEM, aadA and tet $\mathrm{A}$ in the tested isolates, respectively. While in case of ciprofloxacin, the plasmid mediated quinolone resistance $(q n r \mathrm{~S})$ gene was detected only in $20 \%$ of resistant strains. Also, gentamicin resistance rate was $60 \%$ in spite of presence of $\mathrm{aadA}$ gene in all ESBL producing isolates. This might be conducted to presence of another resistance mechanism responsible for a significant loss of antibiotic susceptibility (Davin-Regli et al. 2008).

Also, in the current study, some of plasmid associated genes of ESBL producing E. coli isolates were investigated. It was proposed that the iss gene can be used as a marker for distinguishing between APEC and commensal strains (Kwon et al. 2008). In the current study, all tested strains of ESBL E. coli were positive for iss gene. Similar results were reported in Egypt (100\%) (Ammar et al. 2015) and Kora (100\%) (Jeong et al. 2012). Yaguchi et al. (2007) reported that iss gene is most frequently detected in E. coli strains isolated from chicken. The ompA gene is an essential constituent of outer membranes, thus is required for the cell surface structural integrity (Chen et al. 1980). The ompA gene was detected in all tested strains in the current study. In accordance, Johnson et al. (2008) detected ompA gene in all APEC isolates, while, Abd El-Mongy et al. (2018) detected ompA gene in all isolated E. coli serotypes except O153. Meanwhile, eae and CFA/I genes could not be detected in all tested ESBL producing E. coli strains. This might be due to $(C F A / \mathrm{I})$ fimbriae are prevalent among ETEC strains than extra-intestinal strains (Nataro and Kaper 1998), in addition, the eae gene is responsible for intimate adherence on epithelial cells, which typical for EHEC and EPEC strains (Frankel et al. 1998).

Our results showed that all ESBL $E$. coli strains had two virulence genes with antibiotic resistance genes. Thus, the co-occurrence of these antibiotic resistance and virulence plasmid associated genes confirmed that acquisition of antimicrobial resistance genes by ESBL producing E. coli, which associated with increased virulence (Ammar et al. 2015).

Based on the current findings, it can be clearly demonstrated that E. coli is a major pathogen associated with arthritis infection of poultry in Egypt. Meanwhile, the high levels of multidrug resistant were detected. These might be attributed to a combination of antibiotic resistant genes, which could cause colibacillosis treatment failure, in addition to multiple virulence determinants in plasmids of ESBL producing $E$. coli isolates

Whatever, studding of virulence and resistance genes is very important to know the pathogenicity of the present microorganisms, but more investigation about other mechanism of resistance is necessary. Based on the reported data herein, the high incidence rate of virulent multidrug resistant $E$. coli strains among chicken flocks requires 
urgent intervention approaches to control spread of these strains to humans through poultry and its products in Egypt.

\section{Disclosure Statement}

No competing financial interests exist.

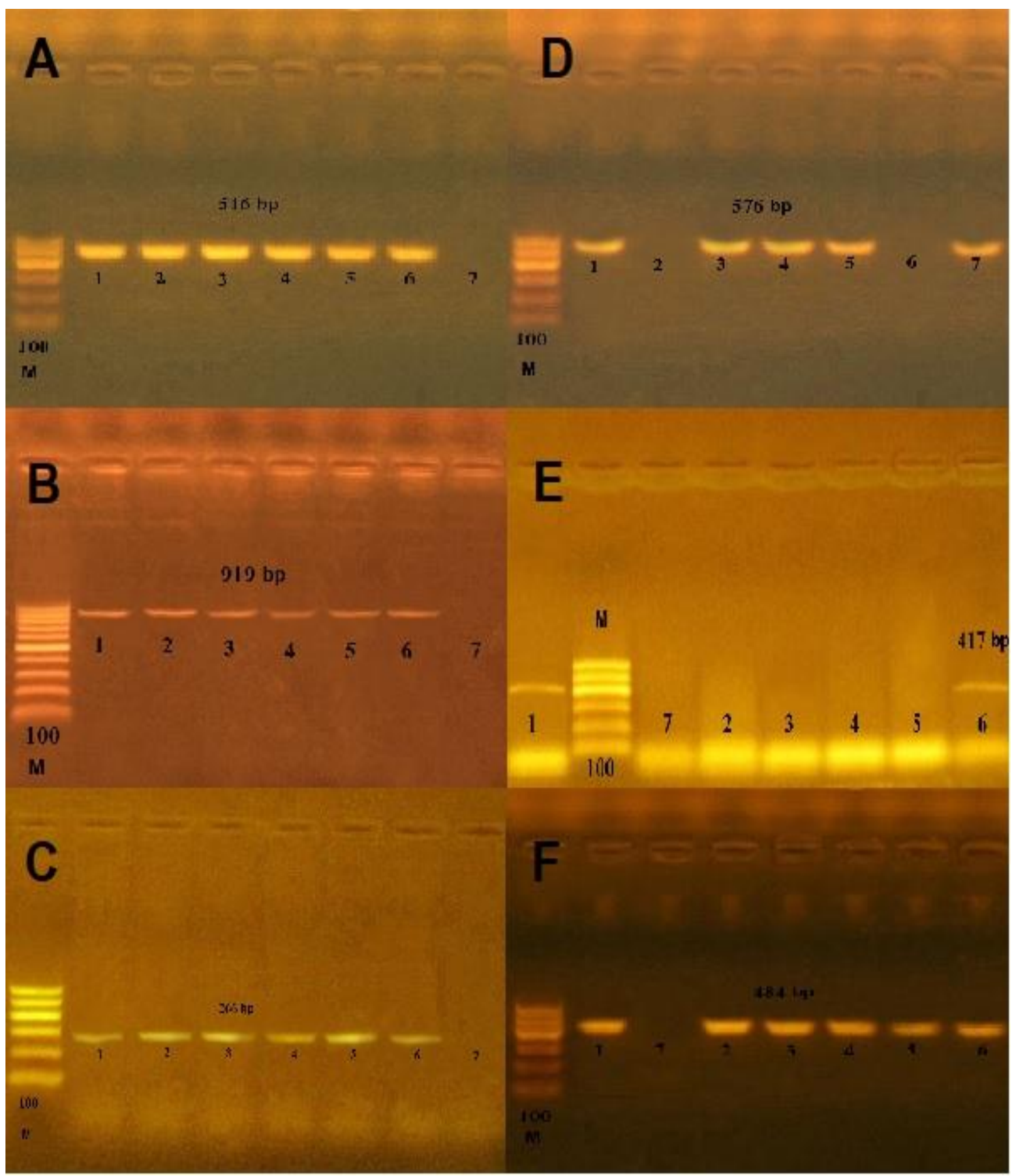

Figure 1:-Agarose gel electrophoresis pattern for amplification of antibiotic resistance and virulence plasmid associated (A; blaTEM, B; ompA, C; iss, D; tetA, E; qnrS, F; aadA) genes of identified ESBL E. coli isolates; 2-6; positive isolates, 7; Negative control, 1; Positive control, M: DNA molecular size marker (100 bp) 
Table 1:-Primers used for pcr amplification of virulence and antibiotic resistance plasmid associated genes of ESBL E. coli

\begin{tabular}{|c|c|c|c|c|}
\hline Target genes & Primers sequences $\left(5^{`} \rightarrow 3^{`}\right)$ & $\begin{array}{l}\text { Size } \\
\text { bp } 1\end{array}$ & ${ }^{0} \mathrm{C}^{2}$ & Reference \\
\hline \multirow{2}{*}{$b^{\prime} a_{\mathrm{TEM}}$} & ATCAGCAATAAACCAGC & \multirow{2}{*}{516} & \multirow{2}{*}{50} & \multirow{2}{*}{$\begin{array}{l}\text { Colom et al. } \\
(2003)\end{array}$} \\
\hline & CCCCGAAGAACGTTTTC & & & \\
\hline \multirow{2}{*}{$b^{b l a} a_{\text {СТХ-М }}$} & ATGTGCAGYACCAGTAARGTKATGGC & \multirow{2}{*}{592} & \multirow{2}{*}{55} & \multirow{2}{*}{$\begin{array}{l}\text { Mulvey et al. } \\
\quad(2003)\end{array}$} \\
\hline & TGGGTRAARTARGTSACCAGAAYSAGCGG & & & \\
\hline \multirow{2}{*}{$b l a_{\mathrm{SHV}}$} & TTATCTCCCTGTTAGCCACC & \multirow{2}{*}{795} & \multirow{2}{*}{55} & \multirow{2}{*}{$\begin{array}{l}\text { Dierikx et al. } \\
\text { (2010) }\end{array}$} \\
\hline & GATTTGCTGATTTCGCTCGG & & & \\
\hline \multirow{2}{*}{ ompA } & AGCTATCGCGATTGCAGTG & \multirow{2}{*}{919} & \multirow{2}{*}{58} & \multirow{2}{*}{$\begin{array}{c}\text { Ewers et al. } \\
(2007)\end{array}$} \\
\hline & GGTGTTGCCAGTAACCGG & & & \\
\hline \multirow{2}{*}{ eae $\mathbf{A}$} & ATGCTTAGTGCTGGTTTAGG & \multirow{2}{*}{248} & \multirow{2}{*}{51} & \multirow{2}{*}{$\begin{array}{l}\text { Bisi-Johnson et } \\
\text { al. (2011) }\end{array}$} \\
\hline & GCCTTCATCATTTCGCTTTC & & & \\
\hline \multirow[b]{2}{*}{ iss } & ATGTTATTTTCTGCCGCTCTG & \multirow{2}{*}{266} & \multirow{2}{*}{54} & \multirow{2}{*}{$\begin{array}{c}\text { Yaguchi et al. } \\
\text { (2007) }\end{array}$} \\
\hline & CTATTGTGAGCAATATACCC & & & \\
\hline \multirow{2}{*}{ CFA/I } & GCTCTGACCACAATGTTGA & \multirow{2}{*}{364} & \multirow{2}{*}{50} & \multirow{2}{*}{$\begin{array}{l}\text { Ghosal et al. } \\
\text { (2007) }\end{array}$} \\
\hline & TTACACCGGATGCAGAATA & & & \\
\hline \multirow{2}{*}{ TetA } & GGTTCACTCGAACGACGTC & \multirow{2}{*}{576} & \multirow{2}{*}{$\mathbf{5 0}$} & \multirow{2}{*}{$\begin{array}{l}\text { Randall et al. } \\
\text { (2004) }\end{array}$} \\
\hline & CTGTCCGACAAGTTGCATGA & & & \\
\hline \multirow{2}{*}{$q n r S$} & ACGACATTCGTCAACTGCAA & \multirow{2}{*}{417} & \multirow{2}{*}{55} & \multirow{2}{*}{$\begin{array}{c}\text { Robicsek et al. } \\
\text { (2006) }\end{array}$} \\
\hline & TAAATTGGCACCCTGTAGGC & & & \\
\hline add & TATCAGAGGTAGTTGGCGTCAT & 484 & 54 & Randall et al. \\
\hline $\operatorname{ara} \mathrm{A}$ & GTTCCATAGCGTTAAGGTTTCATTT & & 34 & (2004) \\
\hline
\end{tabular}

1 bp; Base pair, ${ }^{2}$ Annealing Temperature, qnrS; plasmid mediated quinolone resistance gene, ompA; outer membrane protein A gene, eaeA; intimin E. coli attaching and effacing gene, iss; increased serum survival gene, $\operatorname{aadA}$; streptomycin/spectinomycin adenylyltransferase gene, bla; $\beta$-lactamase genes, tetA; tetracycline resistance gene A, CFA/I; colonization factor antigen I

Table 2:-Antibiotic resistance patterns of E. coli isolates

\begin{tabular}{|c|c|c|}
\hline Pattern & Antimicrobial resistance pattern & No of $E$. coli isolates (\%) \\
\hline 1 & AML - S - CN - CIP - DO & $5(12.5)$ \\
\hline 2 & AML - S - CN - DO & $5(12.5)$ \\
\hline 3 & AML - S - CIP - CN & $4(10)$ \\
\hline 4 & AML - S - CIP - DO & $15(37.5)$ \\
\hline 5 & AML - S - CIP & $4(10)$ \\
\hline 6 & AML - S - DO & $7(17.5)$ \\
\hline \multicolumn{2}{|r|}{ Total } & $40(100)$ \\
\hline
\end{tabular}

AML; amoxicillin, S; streptomycin, CN; gentamycin, CIP; ciprofloxacin, DO; doxycycline

Table 3:-Antibiotic resstant profiles and contribution of antibiotic resistance and virulence plasmid associated genes in Esbl E.coli isolates

\begin{tabular}{|c|c|c|c|}
\hline Strain & Phenotypic resistant profile & Genotypic resistant profile & $\begin{array}{c}\text { Virulence gene } \\
\text { profile }\end{array}$ \\
\hline 1 & AML-S-CN-CIP-DO & $b l a_{\mathrm{TEM}}, \operatorname{aad\mathrm {A},tet\mathrm {A}}$ & iss, omp A \\
\hline 2 & AML- S-DO & $b l a_{\mathrm{TEM}}, \operatorname{aad\mathrm {A}}, t e t \mathrm{~A}$ & iss, omp A \\
\hline 3 & AML-S-CN-CIP & bla $_{\mathrm{TEM},}$ aadA, & iss, omp A \\
\hline 4 & AML-S-DO & $b l a_{\mathrm{TEM}}, \operatorname{add\mathrm {A},}$ tet $\mathrm{A}$ & iss, omp A \\
\hline 5 & AML-S-CN-CIP-DO & $b l a_{\mathrm{TEM}}$ aad $\mathrm{A}, q n r S$, tet $\mathrm{A}$ & iss, ompA \\
\hline
\end{tabular}

AML; amoxicillin, S; streptomycin, CN; gentamycin, CIP; ciprofloxacin, DO; doxycycline, qnrS; plasmid mediated quinolone resistance gene, ompA; outer membrane protein A gene, iss; increased serum survival gene, aadA; streptomycin/spectinomycin adenylyltransferase gene, bla ${ }_{\mathrm{TEM}} ; \beta$-lactamase gene, tet $\mathrm{A}$; tetracycline resistance gene. 


\section{References:-}

1. Abd El-Mongy, M, G Abd-El-Moneam, A Moawad and A Mohammed, 2018. Serotyping and Virulence Genes Detection in Escherichia coli Isolated from Broiler Chickens. Journal of Biological Sciences. 18: 46-50.

2. Ahmed, A M and T Shimamoto, 2011. Molecular characterization of antimicrobial resistance in Gram-negative bacteria isolated from bovine mastitis in Egypt. Microbiology and immunology. 55: 318-327.

3. Ahmed, O M, P Pangloli, C-A Hwang, S Zivanovic, T Wu, D D'souza and F A Draughon, 2015. The occurrence of Listeria monocytogenes in retail ready-to-eat meat and poultry products related to the levels of acetate and lactate in the products. Food Control. 52: 43-48.

4. Al-Agamy, M H, 2013. Phenotypic and molecular characterization of extended-spectrum $\beta$-lactamases and AmpC $\beta$-lactamases in Klebsiella pneumoniae. Pakistan journal of pharmaceutical sciences. 26.

5. Alekshun, M N and S B Levy, 2007. Molecular mechanisms of antibacterial multidrug resistance. Cell. 128: 1037-1050.

6. Ammar, A, M El-Hamid, S Eid and A El Oksh, 2015. Insight into antimicrobial resistance and virulence genes of emergent multidrug resistant avian pathogenic Escherichia coli in Egypt: How closely related are they. Rev. Med. Vet. 166: 304-314.

7. Bisi-Johnson, M A, C L Obi, S D Vasaikar, K A Baba and T Hattori, 2011. Molecular basis of virulence in clinical isolates of Escherichia coli and Salmonella species from a tertiary hospital in the Eastern Cape, South Africa. Gut pathogens. 3: 9.

8. Blaak, H, R A Hamidjaja, A H van Hoek, L de Heer, A M de Roda Husman and F M Schets, 2014. Detection of extended-spectrum beta-lactamase (ESBL)-producing Escherichia coli on flies at poultry farms. Appl. Environ. Microbiol. 80: 239-246.

9. Chen, R, W Schmidmayr, C Krämer, U Chen-Schmeisser and U Henning, 1980. Primary structure of major outer membrane protein II (ompA protein) of Escherichia coli K-12. Proceedings of the National Academy of Sciences. 77: 4592-4596.

10. CLSI, 2011. Clinical and laboratory standards institute. Performance standards for antimicrobial susceptibility testing.

11. CLSI, 2014. Clinical and Laboratory Standards Institute; Performance Standards for Antimicrobial Susceptibility Testing. 24th Informational Supplement M100-S24. CLSI, Wayne, PA, USA.

12. Colom, K, J Pérez, R Alonso, A Fernández-Aranguiz, E Lariño and R Cisterna, 2003. Simple and reliable multiplex PCR assay for detection of bla TEM, bla SHV and bla OXA-1 genes in Enterobacteriaceae. FEMS microbiology letters. 223: 147-151.

13. Davin-Regli, A, J-M Bolla, C E James, J-P Lavigne, J Chevalier, E Garnotel and A Molitor, 2008. Membrane permeability and regulation of drug "influx and efflux" in enterobacterial pathogens. Current drug targets. 9: 750-759.

14. Dierikx, C, A van Essen-Zandbergen, K Veldman, H Smith and D Mevius, 2010. Increased detection of extended spectrum beta-lactamase producing Salmonella enterica and Escherichia coli isolates from poultry. Veterinary microbiology. 145: 273-278.

15. Dutil, L, R Irwin, R Finley, L K Ng, B Avery, P Boerlin, A-M Bourgault, L Cole, D Daignault and A Desruisseau, 2010. Ceftiofur resistance in Salmonella enterica serovar Heidelberg from chicken meat and humans, Canada. Emerging infectious diseases. 16: 48.

Edward, P and W Ewings, 1972. Identification of enterobacteriacae, Minneapolis. Burgess Publishing Co.

16. Eid, S and A Erfan, 2013. Characterization of E. coli associated with high mortality of poultry flocks. Assiut Vet. Med. J. 59: 51-61.

17. El-Shazly, D, S Nasef, F Mahmoud and D Jonas, 2017. Expanded spectrum $\beta$-lactamase producing Escherichia coli isolated from chickens with colibacillosis in Egypt. Poultry science. 96: 2375-2384.

18. El Tawab, A A, A M Ammar, S A Nasef and R M Reda, 2015. Prevalence of E. coli in diseased chickens with its antibiogram pattern. Benha Veterinary Medical Journal. 28: 224-230.

19. Ewers, C, G Li, H Wilking, S Kießling, K Alt, E-M Antáo, C Laturnus, I Diehl, S Glodde and T Homeier, 2007. Avian pathogenic, uropathogenic, and newborn meningitis-causing Escherichia coli: how closely related are they? International Journal of Medical Microbiology. 297: 163-176.

20. Finegold, S M and W T Martin, 1982. Diagnostic Microbiology 6th Ed. C.V. Mosby Co. St. Louis Toronto, Londan.

21. Frankel, G, A D Phillips, I Rosenshine, G Dougan, J B Kaper and S Knutton, 1998. Enteropathogenic and enterohaemorrhagic Escherichia coli: more subversive elements. Molecular microbiology. 30: 911-921. 
22. Ghosal, A, R Bhowmick, R K Nandy, T Ramamurthy and N S Chatterjee, 2007. PCR-based identification of common colonization factor antigens of enterotoxigenic Escherichia coli. Journal of clinical microbiology. 45: 3068-3071.

23. Gomis, S M, C Riddell, A A Potter and B J Allan, 2001. Phenotypic and genotypic characterization of virulence factors of Escherichia coli isolated from broiler chickens with simultaneous occurrence of cellulitis and other colibacillosis lesions. Canadian Journal of Veterinary Research. 65: 1.

24. Hawkey, P M and A M Jones, 2009. The changing epidemiology of resistance. Journal of Antimicrobial Chemotherapy. 64: i3-i10.

25. Jeong, Y-W, T-E Kim, J-H Kim and H-J Kwon, 2012. Pathotyping avian pathogenic Escherichia coli strains in Korea. Journal of veterinary science. 13: 145-152.

26. Johnson, T J, Y Wannemuehler, C Doetkott, S J Johnson, S C Rosenberger and L K Nolan, 2008. Identification of minimal predictors of avian pathogenic Escherichia coli virulence for use as a rapid diagnostic tool. Journal of clinical microbiology. 46: 3987-3996.

27. Khater, E S and H W Sherif, 2014. Rapid Detection of Extended Spectrum [Beta]-lactamase (ESBL) Producing Strain of Escherichia coli in Urinary Tract Infections Patients in Benha University Hospital, Egypt. British Microbiology Research Journal. 4: 443.

28. Kwon, S-G, S-Y Cha, E-J Choi, B Kim, H-J Song and H-K Jang, 2008. Epidemiological prevalence of avian pathogenic Escherichia coli differentiated by multiplex PCR from commercial chickens and hatchery in Korea. Journal of Bacteriology and Virology. 38: 179-188.

29. Laube, H, A Friese, C Von Salviati, B Guerra, A Käsbohrer, L Kreienbrock and U Roesler, 2013. Longitudinal monitoring of Esbl/Ampc-Producing Escherichia coli in German broiler chicken fattening farms. Applied and environmental microbiology. AEM. 00856-00813.

30. Machado, E, R Cantón, F Baquero, J-C Galán, A Rollán, L Peixe and T M Coque, 2005. Integron content of extended-spectrum- $\beta$-lactamase-producing Escherichia coli strains over 12 years in a single hospital in Madrid, Spain. Antimicrobial agents and chemotherapy. 49: 1823-1829.

31. Mulvey, M R, G Soule, D Boyd, W Demczuk, R Ahmed and M-p S T C C S Group, 2003. Characterization of the first extended-spectrum beta-lactamase-producing Salmonella isolate identified in Canada. Journal of clinical microbiology. 41: 460-462.

32. Nataro, J P and J B Kaper, 1998. Diarrheagenic escherichia coli. Clinical microbiology reviews. 11: 142-201.

33. Oh, J, M Kang, J Kim, B An, E Song, J Kim, E Shin, M Kim, J Kwon and Y Kwon, 2011. Characterization of Escherichia coli isolates from laying hens with colibacillosis on 2 commercial egg-producing farms in Korea. Poultry science. 90: 1948-1954.

34. Orskov, I, F Orskov, B Jann and K Jann, 1977. Serology, chemistry, and genetics of O and K antigens of Escherichia coli. Bacteriological reviews. 41: 667.

35. Quinn, P, M Carter, B Markey, W Donnoly and F Leonard, 2002. Veterinary microbiology and microbial disease. 166-1117 Osney Mead. Oxford first LTd, Registered at the United Kingdom.

36. Rahman, M, M Samad, M Rahman and S Kabir, 2004. Bacterio-pathological studies on salmonellosis, colibacillosis and pasteurellosis in natural and experimental infections in chickens. Bangladesh Journal of Veterinary Medicine. 2: 1-8.

37. Randall, L, S Cooles, M Osborn, L Piddock and M J Woodward, 2004. Antibiotic resistance genes, integrons and multiple antibiotic resistance in thirty-five serotypes of Salmonella enterica isolated from humans and animals in the UK. Journal of Antimicrobial Chemotherapy. 53: 208-216.

38. Rasheed, B, 2011. Isolation and identification of bacteria causing arthritis in chickens. Iraqi Journal of Veterinary Sciences. 25: 93-95.

39. Robicsek, A, J Strahilevitz, G A Jacoby, M Macielag, D Abbanat, C H Park, K Bush and D C Hooper, 2006. Fluoroquinolone-modifying enzyme: a new adaptation of a common aminoglycoside acetyltransferase. Nature medicine. 12: 83 .

40. Sahoo, T K, L Sahoo, L N Sarangi, S K Panda and H K Panda, 2012. Prevalence, isolation, characterisation and antibiogram study of pathogenic Escherichia coli from different poultry farms of Odisha. Journal of Advanced Veterinary Research. 2: 169-172.

41. Saidi, B, P Mafirakureva and J Mbanga, 2012. Antimicrobial resistance of Escherichia coli isolated from chickens with colibacillosis in and around Harare, Zimbabwe. Avian diseases. 57: 152-154.

42. Shaza, Z M, 2016. Advanced microbiological studies on the bacterial causes of respiratory affections of poultry. Master thesis Bacteriology Department, Faculty of veterinary medicine Beni-Suef University, Egypt.

43. Smith, J L, P M Fratamico and N W Gunther, 2007. Extraintestinal pathogenic Escherichia coli. Foodborne pathogens and disease. 4: 134-163. 
44. Srinivasan, P, G A Balasubramaniam, T R G K Murthy and P Balachandran, 2013. Bacteriological and pathological studies of egg peritonitis in commercial layer chicken in Namakkal area. Asian Pacific journal of tropical biomedicine. 3: 988-994.

45. Su, L-H, C Chu, A Cloeckaert and C-H Chiu, 2008. An epidemic of plasmids? Dissemination of extendedspectrum cephalosporinases among Salmonella and other Enterobacteriaceae. FEMS Immunology \& Medical Microbiology. 52: 155-168.

46. Tawfik, R G, S A Khalil, H F Ellakany and H A Torky, 2016. Mycoplasma Synoviae and other Associated Bacteria Causing Arthritis in Chicken. Alexandria Journal for Veterinary Sciences. 49.

47. WHO, 2014. World Health Organization; Antimicrobial resistance: Global report on surveillance. Available at http://www.who.int/drugresistance/documents/surveillancereport/en/.

48. Yaguchi, K, T Ogitani, R Osawa, M Kawano, N Kokumai, T Kaneshige, T Noro, K Masubuchi and Y Shimizu, 2007. Virulence factors of avian pathogenic Escherichia coli strains isolated from chickens with colisepticemia in Japan. Avian diseases. 51: 656-662. 